\title{
Effects of mobile texting and gaming on gait with obstructions under different illumination levels
}

\author{
Jaeyun Cha ${ }^{a}$, Hyunjin Kim ${ }^{b}$ Jaemyoung Park ${ }^{c}$, Changho Song ${ }^{d}$ \\ ${ }^{a}$ Department of Rehabilitation Medicine, Sahmyook Seoul Medical Center, Seoul, Republic of Korea \\ ${ }^{b}$ Department of Rehabilitation Medicine, Hanyang University Guri Hospital, Guri, Republic of Korea \\ 'Department of Rehabilitation Medicine, Seoul Medical Center, Seoul, Republic of Korea \\ ${ }^{\mathrm{d} D e p a r t m e n t}$ of Physical Therapy, College of Health and Welfare, Sahmyook University, Seoul, Republic of Korea
}

Objective: This study was conducted to test the effects of mobile texting and gaming on gait with obstructions under different illumination levels.

Design: Cross-sectional study.

Methods: Twelve healthy adults aged 20 to 36 years (mean 23.5 years) were tested under six different conditions. All participants used touchscreen smartphones. Testing conditions included: 1) Walking with an obstruction under a bright illumination level; 2) walking with an obstruction with a low level of illumination; 3) walking with an obstruction while texting under a bright illumination level; 4) walking with an obstruction while texting with a low level of illumination; 5) walking with an obstruction while gaming under a bright illumination level; and 6) walking with an obstruction while gaming with a low level of illumination. All participants were asked to text the Korean national anthem by their own phone and play Temple Run 2 using an iPhone 5. Gait variances were measured over a distance of $3 \mathrm{~m}$, and the mean value after three trials was used. A gait analyzer was used to measure the data. Results: Compared to normal gait with obstruction, gait speed, step length, stride length, step time, stride time, cadence while texting and gaming showed significant differences $(p<0.05)$. Differences between the illumination levels included gait speed, step length, stride length, and step time $(p<0.05)$ with no significant differences in stride time and cadence.

Conclusions: Dual-tasking using a smartphone under low levels of illumination lowers the quality of gait with obstructions.

Key Words: Cell phones, Gait, Task performance, Lighting

\section{Introduction}

Mobile phones are used for a significant portion of everyday life in all age groups. Seventy-seven percent of the world's population have mobile phones, and they have been recognized as a cost-effective communication tool [1]. Although mobile phones provide great convenience, they cause risks in certain situations [2]. Pedestrian use of mobile phones increases cognitive distraction, decreases the ability to react to sudden changes, and increases disturbing actions causing injury or even death [3-6]. For example, in a virtual experiment, it was shown that texting while walking in- creases the chance of being hit by a car or a motorcycle; moreover, texting is a distraction from the surroundings [7]. Previous research on texting while walking has shown that pedestrians walk slower with less traffic awareness [3,5]. The act of texting while walking changes the consciousness of walking affected by the working memory and executive control [8].

In order to write a text, the attention must be focused on a small screen. Because of gaze fixation on the mobile screen, the visual information of the surrounding environment significantly drops [9]. Also, a heightened attention level is necessary while texting for agile hand movements. Atten-

Received: 6 May, 2015 Revised: 27 May, 2015 Accepted: 28 May, 2015

Corresponding author: Changho Song

Department of Physical Therapy, College of Health and Welfare, Sahmyook University, 815 Hwarang-ro, Nowon-gu, Seoul 139-742, Republic of Korea Tel: 82-2-3399-1637 Fax: 82-2-3399-1639 E-mail: chsong@syu.ac.kr

(c) This is an Open-Access article distributed under the terms of the Creative Commons Attribution Non-Commercial License (http://creativecommons.org/licens es/by-nc/4.0) which permits unrestricted non-commercial use, distribution, and reproduction in any medium, provided the original work is properly cited.

Copyright $@ 2015$ Korean Academy of Physical Therapy Rehabilitation Science 
tion is defined as personal processing ability [10], and multi-tasking can be used as a tool to measure the attention level in processing data. Each individual has a limited central processing capacity, which is required in data processing. If multi-tasking exceeds the level of processing capacity, multi-tasking will be affected [11]. As a result, multi-tasking cannot be used as a tool to measure the processing capacity level. Although safe walking requires both physical ability and sensory ability, multi-tasking (such as texting and gaming) disturbs the working memory and causes situational errors [12].

People multi-task most of the time in pedestrian activity. However, even simple multi-tasking causes negative impacts on body balance and obstruction avoidance [13-15]. If one cannot locate a possible obstruction because of a lower awareness level, a trip or a fall will be expected [16]. Obstructions with different heights, widths, or depths require locomotion patterns of jumping over, stepping down, and going around. These locomotion patterns are common when facing obstructions and are compulsory elements in successful locomotion. Locomotion patterns cause changes in gait patterns and demands for physical and conscious qualifications $[17,18]$.

While walking, the visual system provides important information on the surroundings and contributes to route planning and maintaining body stability $[19,20]$. The availability of visual information on the location of an obstruction significantly affects how a pedestrian deals with the obstruction. Loss of visual information while approaching an obstruction increases the risk of incorrect foot placement by $50 \%$ [21].

Although research has been conducted on the risk of mobile phone use while walking, research on multi-tasking using mobile phones is inadequate. Therefore, this study was conducted to test the influence of multi-tasking on gait in different illumination settings.

\section{Methods}

\section{Subjects}

Twelve healthy adults from Sahmyook University in Seoul were included in the study. All participants were free of any medical conditions and used touchscreen smartphones. The study excluded candidates with abnormal limbs, a history of nerve disease, inability to use a touch screen, and less than six months of smartphone experience. The study was conducted after obtaining approval from the ethics committee of Sahmyook University. Prior to participation, subjects received an explanation of the objective and methods of the study and completed a consent of agreement.

\section{Procedures}

The experiment was performed inside a flat lecture room in Sahmyook University. Testing conditions included: 1) Walking with an obstruction under a bright illumination level; 2) walking with an obstruction with a low level of illumination; 3) walking with an obstruction while texting under a bright illumination level; 4) walking with an obstruction while texting with a low level of illumination; 5) walking with an obstruction while gaming under a bright illumination level; and 6) walking with an obstruction while gaming with a low level of illumination. All participants were asked to text the Korean national anthem by their own phone and play Temple Run 2 (Imangi Studios, Raleigh, NC, USA) using an iPhone 5 (Apple Inc., Cupertino, CA, USA). Participants began texting and gaming just before they began walking. To minimize light adaptation, dark and light shades were applied correspondingly. Gait variance was measured for a length of $3 \mathrm{~m}$, excluding the $1 \mathrm{~m}$ walked before and after the tested area. The experiment value was the mean value after three trials for each subject. To measure the data, a gait analyzing tool (OptoGait, 2010; Microgate Srl, Bolzano, Italy) was used. The analyzing tool contained two transmitters, a $1 \mathrm{~m}$ receptor stick, and a webcam (Logitech

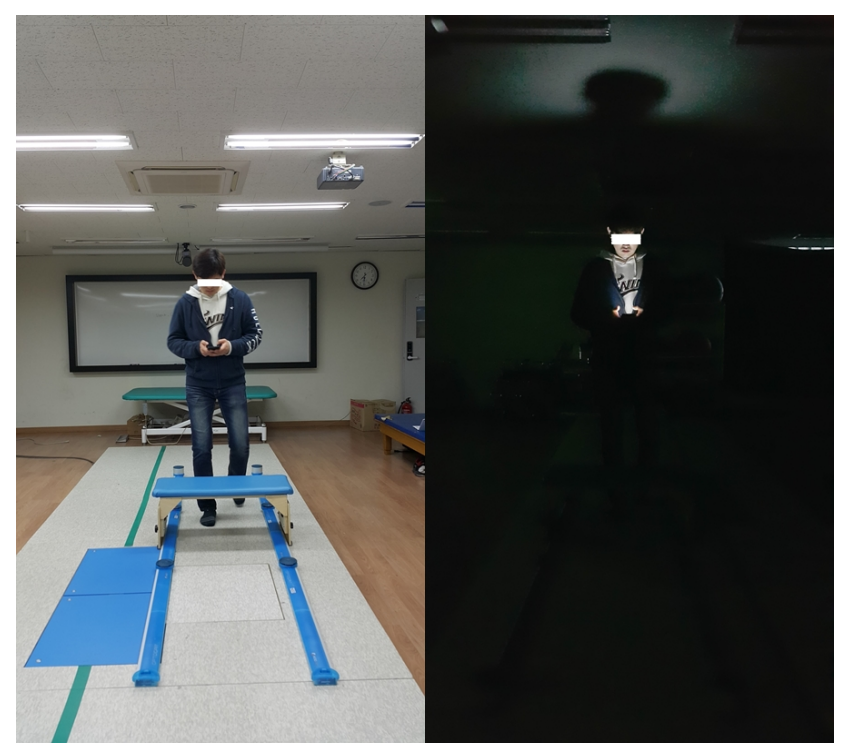

Figure 1. Texting and gaming on gait while walking with an obstructions under different illumination levels. 
Webcam Pro 9000; Logitech International S.A., Lausanne, Switzerland). OptoGait software (version 1.5.0.0; Microgate Srl) was used to analyze the gait data. The intra-class correlation coefficients for test-retest reliability of OptoGait were between 0.785 and 0.982 [22]. A table $75 \mathrm{~cm}$ in length, $30 \mathrm{~cm}$ in width, and $30 \mathrm{~cm}$ in height was used to create an obstruction (Figure 1).

\section{Data analysis}

Statistical software (IBM SPSS Statistics version 19.0; IBM Co., Armonk, NY, USA) was used for data analysis.

Table 1. General characteristics of subjects

$(\mathrm{N}=12)$

\begin{tabular}{lc}
\hline \multicolumn{1}{c}{ Characteristic } & Value \\
\hline Gender (male/female) & $6 / 6$ \\
Age (y) & $23.50(4.89)$ \\
Height (cm) & $167.42(7.88)$ \\
Weight (kg) & $63.92(10.25)$ \\
Dominant hand (right/left) & $11 / 1$ \\
Phone OS type (iOS/Android) & $4 / 8$ \\
Duration using a mobile phone (y) & $10.00(2.45)$ \\
Time using a mobile phone per day (h) & $3.17(1.11)$ \\
\hline
\end{tabular}

Values are presented as number only or mean (SD).
The experiment used descriptive statistics for each participant's general features. All variables were compared among the different conditions using repeated two-way analysis of variance. A significance level of $p<0.05$ was applied to all analyses.

\section{Results}

The general features of the 12 participants are shown in Table 1. The participants ranged in age from 20 to 36 years with a mean age of 23.5 years. They averaged 3.17 hours of smartphone use per day. Compared to the normal gait, gait speed, step length, stride length, step time, stride time, cadence while texting and gaming showed significant differences $(p<0.05)$ (Figure 2). Differences between contrasting illumination levels included gait speed, step length, stride length, and step time $(p<0.05)$ with no significant differences in stride time or cadence (Table 2).

\section{Discussion}

Multiple concurrent tasks often require attention during daily activities [6]. To adapt to the external environment,
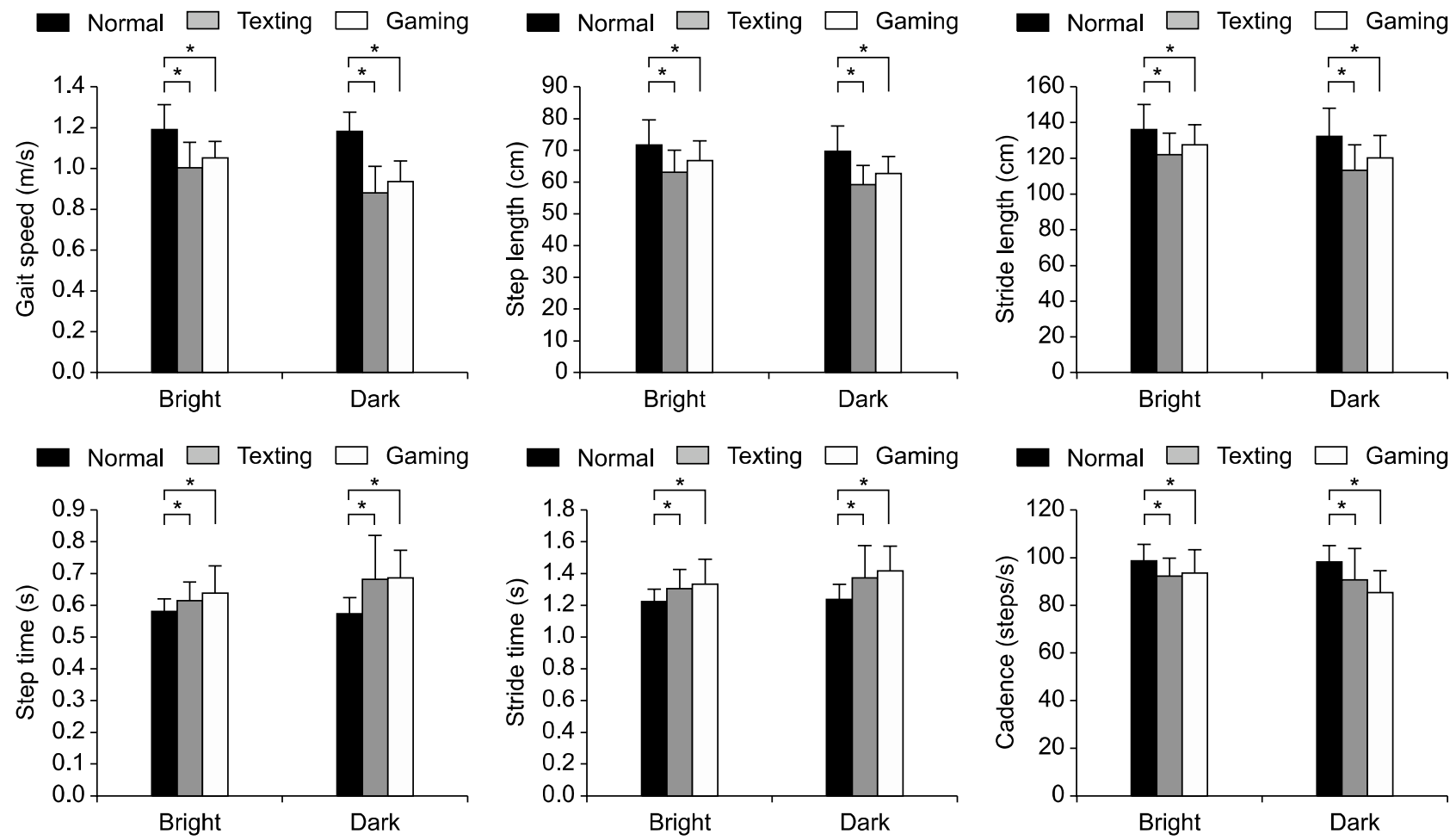

Figure 2. Differences of gait parameters in normal, texting, and gaming gait. "Significant differences between normal and texting, normal, and gaming $(p<0.05)$. 
Table 2. Comparison of normal, texting, and gaming gait in different illumination levels

$(\mathrm{N}=12)$

\begin{tabular}{|c|c|c|c|c|c|c|}
\hline \multirow{2}{*}{ Parameter } & \multicolumn{2}{|c|}{ Normal } & \multicolumn{2}{|c|}{ Texting } & \multicolumn{2}{|c|}{ Gaming } \\
\hline & Bright & Dark & Bright & Dark & Bright & Dark \\
\hline Speed $(\mathrm{m} / \mathrm{s})$ & $1.19(0.12)$ & $1.18(0.10)$ & $1.00(0.12)$ & $0.88(0.13)$ & $1.05(0.09)$ & $0.94(0.10)^{\mathrm{a}, \mathrm{b}}$ \\
\hline Step length (cm) & 71.57 (8.07) & $69.72(7.77)$ & $63.01(6.80)$ & $59.38(5.77)$ & $66.73(6.21)$ & $62.70(5.64)^{\mathrm{a}, \mathrm{b}}$ \\
\hline Stride length $(\mathrm{cm})$ & 136.04 (13.97) & $132.10(15.72)$ & $122.25(11.57)$ & $113.53(13.86)$ & $127.93(11.25)$ & $120.81(12.36)^{a, b}$ \\
\hline Step time (s) & $0.58(0.04)$ & $0.58(0.04)$ & $0.61(0.05)$ & $0.68(0.13)$ & $0.64(0.08)$ & $0.69(0.09)^{\mathrm{a}, \mathrm{b}}$ \\
\hline Stride time (s) & $1.23(0.08)$ & $1.24(0.09)$ & $1.31(0.11)$ & $1.37(0.19)$ & $1.33(0.15)$ & $1.42(0.16)^{\mathrm{a}}$ \\
\hline Cadence (step/s) & $98.39(6.71)$ & $97.78(7.07)$ & $92.48(7.35)$ & $90.55(13.05)$ & $92.80(10.42)$ & $86.18(8.43)^{\mathrm{a}}$ \\
\hline
\end{tabular}

Values are presented as mean (SD).

${ }^{\mathrm{a}}$ Significant differences between normal and texting, normal, and gaming conditions $(p<0.05)$. ${ }^{\mathrm{b}}$ Significant differences between bright conditions and dark conditions $(p<0.05)$.

proper posture with good body balance is necessary [23]. Multi-tasking can be defined as performing multiple tasks during the same period of time [24]. Previous multi-tasking research focused on hand motion while walking, verbal activity while walking [25], and simple reflection period time during the gait [26]. Multi-tasking causes a serious influence on gait in adults, slowing the locomotion and requiring a greater base of support $[27,28]$. This effect on gait occurs because the balance system increases in stability when faced with a threat [29,30]. Disturbances to stability can occur in a chaotic environment; however, executive function and attention are needed to sustain body safety and locomotion pattern [31]. Texting while walking results in negative dynamic stability because it combines a physical task and a cognitive action [31]. Obstructions and the visual system also have an impact on dynamic stability. People normally face obstructions and unorganized roads while walking. Nevertheless, these types of obstructions alter the locomotion pattern. Jumping over an obstruction increases the demand on the locomotion pattern and increases the chance for a fall [32]. The visual system not only provides information on obstructions but also maintains balance [20] and change of route [33]. Multi-tasking is influenced by the fear of falling. Fear of a fall decreases gait speed and step width which may change the locomotion pattern [34].

In this experiment, we studied how smartphone multi-tasking under different illumination levels influenced the gait with obstructions. Compared to gait under normal conditions, texting and gaming caused a significant decrease in gait speed, step length, stride length, and cadence $(p<0.05)$ with an increase in step time and stride time $(p<0.05)$. However, no significant difference was shown between the texting and gaming gait pattern. Sending an email or texting while walking requires focused attention. Gaze transfers or gaze fixations while texting or writing an email alter locomotion patterns [34]. Demura and Uchiyama [35] supported our data by analyzing stride length and gait speed. Also, Lamberg and Muratori [12] reported in their recent experiment that multi-tasking results in cognitive distraction which slows gait speed and causes deviation from a straight path. Harbluk et al. [36] discuss how pedestrians have a slowed gait speed because of their fear of facing obstructions and fear of a fall. Moreover, distractions from multi-tasking exposes a person to more possible threats from the surroundings. Ebersbach et al. [37] reported that young adults from age 20 to 42 years have changed their locomotion pattern because of secondary tasks such as fine motor tasks and finger tapping. Our experiment also supported the idea that multi-tasking has a great impact on gait variables.

The experiment with different illumination levels shows that levels of illumination decreased gait speed, step length, and stride length $(p<0.05)$ and increased step time $(p<0.05)$. Interestingly, stride time increased in both illumination levels while cadence decreased. In a normal gait, visual sight takes a dominant role in body balancing and target change [38]. Visual information also determines gait route, step time, cadence, stride length, and stance phase [19,39-41]. Blurring, disturbing, or occluding sight decreases step length, which can result in foot placement error $[33,42,43]$ and often changes the locomotion pattern and deviation [40]. A mock test with restricted sight decreased the step speed [44]. Previous studies reported that the reasons for decreased step speed are fear of a fall, fear of uncertainty, and fear of exploration. Those reasons can be defined as a conservative strategy $[20,45]$. Choi et al. [46] reported that under low light, gait speed and stance phase ratio of young adults decreased. Studies of elderly participants reported that gait speed and stride length decreased with obstructions. 
Other studies report that they adopt the gait pattern as time increases [47,48]. Interestingly, when elderly people experience a decrease in their visual ability, they have more gait stability by slowing their gait, decreasing step length, and using more double-limb support [26,49]. Studies on young adults show that changes in illumination levels have a great impact on gait speed, step length, stride length, and step time. Visual perceptions of the surroundings can prevent encountering obstructions [20], but restricted visual perceptions may increase the chance of a fall [50].

Our study had some limitations. First, the obstruction was not rearranged between trials. It is possible that candidates were fully aware of the obstruction in all six conditions. Second, the experiment was carried out in a simple and quiet space. Third, we limited the participants to young adults. So there is a risk to generalization of all ages to use a smartphone. Further studies are expected on gait pattern changes with auditory, visual, and other sensory systems.

\section{Conflict of Interest}

The authors declared no potential conflicts of interest with respect to the authorship and/or publication of this article.

\section{References}

1. Schabrun SM, van den Hoorn W, Moorcroft A, Greenland C, Hodges PW. Texting and walking: strategies for postural control and implications for safety. PLoS One 2014;9:e84312.

2. Stavrinos D, Byington KW, Schwebel DC. Distracted walking: cell phones increase injury risk for college pedestrians. J Safety Res 2011;42:101-7.

3. Nasar J, Hecht P, Wener R. Mobile telephones, distracted attention, and pedestrian safety. Accid Anal Prev 2008;40:69-75.

4. Bungum TJ, Day C, Henry LJ. The association of distraction and caution displayed by pedestrians at a lighted crosswalk. J Community Health 2005;30:269-79.

5. Hatfield J, Murphy S. The effects of mobile phone use on pedestrian crossing behaviour at signalized and unsignalized intersections. Accid Anal Prev 2007;39:197-205.

6. Neider MB, McCarley JS, Crowell JA, Kaczmarski H, Kramer AF. Pedestrians, vehicles, and cell phones. Accid Anal Prev 2010;42:589-94.

7. Schwebel DC, Stavrinos D, Byington KW, Davis T, O'Neal EE, de Jong D. Distraction and pedestrian safety: how talking on the phone, texting, and listening to music impact crossing the street. Accid Anal Prev 2012;45:266-71.

8. Rubinstein JS, Meyer DE, Evans JE. Executive control of cognitive processes in task switching. J Exp Psychol Hum Percept Perform 2001;27:763-97.

9. Langer P, Holzner B, Magnet W, Kopp M. Hands-free mobile phone conversation impairs the peripheral visual system to an extent comparable to an alcohol level of 4-5 g $100 \mathrm{ml}$. Hum Psychopharmacol 2005;20:65-6.

10. Woollacott M, Shumway-Cook A. Attention and the control of posture and gait: a review of an emerging area of research. Gait Posture 2002;16:1-14.

11. Kahneman D. Attention and effort. Englewood Cliffs: Prentice-Hall; 1973. p. 246.

12. Lamberg EM, Muratori LM. Cell phones change the way we walk. Gait Posture 2012;35:688-90.

13. Boisgontier MP, Beets IA, Duysens J, Nieuwboer A, Krampe RT, Swinnen SP. Age-related differences in attentional cost associated with postural dual tasks: increased recruitment of generic cognitive resources in older adults. Neurosci Biobehav Rev 2013;37:1824-37.

14. Shumway-Cook A, Woollacott M, Kerns KA, Baldwin M. The effects of two types of cognitive tasks on postural stability in older adults with and without a history of falls. J Gerontol A Biol Sci Med Sci 1997;52:M232-40.

15. Weerdesteyn V, Schillings AM, van Galen GP, Duysens J. Distraction affects the performance of obstacle avoidance during walking. J Mot Behav 2003;35:53-63.

16. Weerdesteyn V, Nienhuis B, Hampsink B, Duysens J. Gait adjustments in response to an obstacle are faster than voluntary reactions. Hum Mov Sci 2004;23:351-63.

17. Byrne JM, Prentice SD. Swing phase kinetics and kinematics of knee replacement patients during obstacle avoidance. Gait Posture 2003; 18:95-104.

18. Lamoureux E, Sparrow WA, Murphy A, Newton RU. The effects of improved strength on obstacle negotiation in community-living older adults. Gait Posture 2003;17:273-83.

19. Rietdyk S, Rhea CK. Control of adaptive locomotion: effect of visual obstruction and visual cues in the environment. Exp Brain Res 2006;169:272-8.

20. Hallemans A, Ortibus E, Meire F, Aerts P. Low vision affects dynamic stability of gait. Gait Posture 2010;32:547-51.

21. Patla AE, Greig M. Any way you look at it, successful obstacle negotiation needs visually guided on-line foot placement regulation during the approach phase. Neurosci Lett 2006;397:110-4.

22. Lee MM, Song CH, Lee KJ, Jung SW, Shin DC, Shin SH. Concurrent validity and test-retest reliability of the OPTOGait Photoelectric cell system for the assessment of spatio-temporal parameters of the gait of young adults. J Phys Ther Sci 2014; 26:81-5.

23. Morioka S, Hiyamizu M, Yagi F. The effects of an attentional demand tasks on standing posture control. J Physiol Anthropol Appl Human Sci 2005;24:215-9.

24. Pellecchia GL, Shockley K, Turvey MT. Concurrent cognitive task modulates coordination dynamics. Cogn Sci 2005;29:53157.

25. Lundin-Olsson L, Nyberg L, Gustafson Y. Attention, frailty, and falls: the effect of a manual task on basic mobility. J Am Geriatr Soc 1998;46:758-61.

26. Chen HC, Schultz AB, Ashton-Miller JA, Giordani B, Alexander NB, Guire KE. Stepping over obstacles: dividing attention impairs performance of old more than young adults. J Gerontol A Biol Sci Med Sci 1996;51:M116-22.

27. Catena RD, van Donkelaar P, Chou LS. Cognitive task effects on 
gait stability following concussion. Exp Brain Res 2007;176:2331.

28. Siu KC, Lugade V, Chou LS, van Donkelaar P, Woollacott MH. Dual-task interference during obstacle clearance in healthy and balance-impaired older adults. Aging Clin Exp Res 2008;20: 349-54.

29. MacLellan MJ, Patla AE. Adaptations of walking pattern on a compliant surface to regulate dynamic stability. Exp Brain Res 2006;173:521-30.

30. Marigold DS, Patla AE. Age-related changes in gait for multi-surface terrain. Gait Posture 2008;27:689-96.

31. Helbostad JL, Vereijken B, Hesseberg K, Sletvold O. Altered vision destabilizes gait in older persons. Gait Posture 2009;30: 233-8.

32. Austin GP, Garrett GE, Bohannon RW. Kinematic analysis of obstacle clearance during locomotion. Gait Posture 1999;10:10920.

33. Reynolds RF, Day BL. Visual guidance of the human foot during a step. J Physiol 2005;569:677-84.

34. Chamberlin ME, Fulwider BD, Sanders SL, Medeiros JM. Does fear of falling influence spatial and temporal gait parameters in elderly persons beyond changes associated with normal aging? J Gerontol A Biol Sci Med Sci 2005;60:1163-7.

35. Demura S, Uchiyama M. Influence of cell phone email use on characteristics of gait. Eur J Sport Sci 2009;9:303-9.

36. Harbluk JL, Noy YI, Trbovich PL, Eizenman M. An on-road assessment of cognitive distraction: impacts on drivers' visual behavior and braking performance. Accid Anal Prev 2007;39: 372-9.

37. Ebersbach G, Dimitrijevic MR, Poewe W. Influence of concurrent tasks on gait: a dual-task approach. Percept Mot Skills 1995;81:107-13.

38. Hallemans A, Beccu S, Van Loock K, Ortibus E, Truijen S, Aerts P. Visual deprivation leads to gait adaptations that are age- and context-specific: II. Kinematic parameters. Gait Posture 2009; 30:307-11.

39. Hollands MA, Marple-Horvat DE. Visually guided stepping un- der conditions of step cycle-related denial of visual information. Exp Brain Res 1996;109:343-56.

40. Jahn K, Strupp M, Schneider E, Dieterich M, Brandt T. Visually induced gait deviations during different locomotion speeds. Exp Brain Res 2001;141:370-4.

41. Rhea CK, Rietdyk S. Visual exteroceptive information provided during obstacle crossing did not modify the lower limb trajectory. Neurosci Lett 2007;418:60-5.

42. Patla AE, Davies TC, Niechwiej E. Obstacle avoidance during locomotion using haptic information in normally sighted humans. Exp Brain Res 2004;155:173-85.

43. Moe-Nilssen R, Helbostad JL, Akra T, Birdedal L, Nygaard HA. Modulation of gait during visual adaptation to dark. J Mot Behav 2006;38:118-25.

44. Elliott DB, Bullimore MA, Patla AE, Whitaker D. Effect of a cataract simulation on clinical and real world vision. Br J Ophthalmol 1996;80:799-804.

45. Iosa M, Fusco A, Morone G, Paolucci S. Walking there: environmental influence on walking-distance estimation. Behav Brain Res 2012;226:124-32.

46. Choi JS, Kang DW, Shin YH, Tack GR. Differences in gait pattern between the elderly and the young during level walking under low illumination. Acta Bioeng Biomech 2014;16:3-9.

47. Rosengren KS, McAuley E, Mihalko SL. Gait adjustments in older adults: activity and efficacy influences. Psychol Aging 1998;13:375-86

48. Gill J, Allum JH, Carpenter MG, Held-Ziolkowska M, Adkin $\mathrm{AL}$, Honegger F, et al. Trunk sway measures of postural stability during clinical balance tests: effects of age. J Gerontol A Biol Sci Med Sci 2001;56:M438-47.

49. Speers RA, Kuo AD, Horak FB. Contributions of altered sensation and feedback responses to changes in coordination of postural control due to aging. Gait Posture 2002;16:20-30.

50. Paquet N, Lajoie Y, Rainville C, Sabagh-Yazdi F. Effect of navigation direction on the dual-task of counting backward during blind navigation. Neurosci Lett 2008;442:148-51. 